\title{
Adult age differences in binding actors and actions in memory for events
}

\author{
Alan W. Kersten, Julie L. Earles, Eileen S. Curtayne, and Jason C. Lane \\ Florida Atlantic University, Boca Raton, Florida
}

\begin{abstract}
Three experiments provide evidence for an age-related deficit in the binding of actors with their actions. Young and older adults were tested on their memory for a series of events, each involving an actor performing a simple action. Older adults had greater difficulty than did young adults at discriminating old events from novel conjunctions of familiar actors and actions, even when the two groups were equated on memory for each of those features in isolation by using a longer retention interval for young adults. These results are consistent with an age-related associative deficit linked to declines in hippocampal and prefrontal cortical functioning. They further provide evidence that age differences in source monitoring are not limited to speech acts but, rather, generalize to more complex actions. Finally, they provide evidence for age differences in susceptibility to conjunction memory errors, stemming from decreased reliance on recollection and increased reliance on familiarity with increased age. Example videos may be downloaded from www.psychonomic.org/archive.
\end{abstract}

Accurate memory for an event requires that one remember not only the constituent features of the event, such as the people involved and the actions that were performed, but also how those features went together. This process of associating people with their actions is an example of binding. Binding involves creating associations among a number of stimulus features in order to represent that they belong together as parts of the same stimulus. Binding is necessary because the different features of a stimulus (e.g., shape, color, or motion) are represented in separate feature maps in the brain and, thus, it is necessary to represent that a feature in one map corresponds to a feature in a second map. This requirement of binding, however, brings with it the possibility for binding errors, in which a feature from one stimulus is mistakenly associated with a feature from another stimulus, causing one to believe that those two features belonged together (see, e.g., Treisman \& Schmidt, 1982).

The ability to successfully bind people with their actions is crucial to being a functioning member of society. For example, one must remember who has lent one some money and who has listened to one's story, so that one can avoid repaying the wrong person and avoid repeatedly telling the same story to the same person. Although everyone may be susceptible to binding errors at one time or another, there is reason to believe that older adults may be particularly prone to errors in the binding of actors with actions. In particular, binding in memory seems to depend on the functioning of the hippocampus (Eichenbaum \& Bunsey, 1995; Giovanello, Schnyer, \& Verfaellie, 2004; Gluck \& Myers, 2001; Henkel, Johnson, \& De Leonardis, 1998; Kroll, Knight, Metcalfe, Wolf, \& Tulving, 1996; O’Reilly \& Rudy, 2001; Squire, 1992) and the prefrontal cortex (Glisky, Rubin, \&
Davidson, 2001; Prabhakaran, Narayanan, Zhao, \& Gabrieli, 2000), and these are some of the most profoundly affected brain areas in normal aging (Davis \& Bernstein, 1992; Raz, 2000; Raz, Rodrigue, Head, Kennedy, \& Acker, 2004; Selkoe, 1992). Furthermore, it has been proposed that impairments in hippocampal and prefrontal cortical functioning cause older adults to exhibit an associative deficit, or a difficulty in binding together the elements of a complex stimulus (Cabeza, 2006; Naveh-Benjamin, 2000; NavehBenjamin, Hussain, Guez, \& Bar-On, 2003). We thus test the prediction in the present research that older adults may be more susceptible than are young adults to binding errors in memory for actors and actions.

A number of prior studies have demonstrated that older adults have greater difficulty than do young adults at binding the attributes of a stimulus together in memory. For example, Chalfonte and Johnson (1996) found that older adults had greater difficulty than did young adults at associating a picture of an object with a particular location in a grid or a particular color in which it was printed, even when the two groups were equated on memory for the individual stimulus features. Furthermore, Mitchell, Johnson, Raye, and D'Esposito (2000) have demonstrated that age differences in the binding of objects with locations are linked to changes in hippocampal and prefrontal cortical functioning. Finally, research on external source monitoring (see Johnson, Hashtroudi, \& Lindsay, 1993) has demonstrated that older adults have greater difficulty than young adults at remembering which person had performed a particular speech act (Bayen, 1999; A. S. Brown, Jones, \& Davis, 1995; Hashtroudi, Johnson, \& Chrosniak, 1989; Rahhal, May, \& Hasher, 2002; Schacter, Kaszniak, Kihlstrom, \& Valdiserri, 1991; Simons, 
Dodson, Bell, \& Schacter, 2004), suggesting that age differences in the binding of features in memory may generalize to the binding of actors and actions.

Although the finding of an age-related decline in external-source-monitoring ability provides some evidence that age differences in binding ability will generalize to the binding of actors and actions, there is reason to be cautious in drawing this conclusion. The actions involved in the above-cited studies were always speech acts - typically, the speaking of a single word. The perceptual information that allows one to determine the source of a speech act (e.g., voice or facial motions) may be much more fleeting and subtle than the information that allows one to determine the source of other, more complex types of actions. In particular, the specific motions involved in carrying out a complex action are constrained by the physical proportions of the person carrying out that action, so that the same action may appear quite different when performed by two differently proportioned people (see, e.g., Cutting \& Kozlowski, 1977). Thus, the particular way an action is performed may provide clues regarding the physical appearance of the person carrying out that action. Given the evidence that age differences in external-sourcemonitoring ability are sometimes reduced when distinctive perceptual cues as to source are available (Bayen \& Murnane, 1996; Ferguson, Hashtroudi, \& Johnson, 1992; Johnson, De Leonardis, Hashtroudi, \& Ferguson, 1995; Spencer \& Raz, 1995), it remains possible that the richer cues to source associated with more complex actions may allow older adults to perform as well as young adults at remembering which actor performed a given action.

A further reason to be cautious in predicting age differences in the binding of actors with actions comes from research on conjunction memory errors. In this research (e.g., Reinitz, Verfaellie, \& Milberg, 1996), participants have been presented with stimuli involving multiple components, such as polysyllabic words (e.g., blackmail, jailbird). When tested on their memory for these stimuli, the participants have been found to be likely to falsely recognize recombined stimuli involving familiar components that did not appear together at encoding (e.g., blackbird). This result would seem to be an example of a binding error. In particular, participants clearly remember the components from which a stimulus was constructed but have difficulty remembering which of those components went together in the same stimulus.

The dual-process framework of Jacoby (1999) has been used to explain the false recognition of conjunction stimuli. In particular, Jones and Jacoby (2001) proposed that conjunction memory errors stem from the familiarity of the features of a stimulus in the absence of conscious recollection of when those features were seen and how they co-occurred. Because conjunction items contain two familiar features, they elicit a strong feeling of familiarity that causes participants to believe that they must have seen them before, even though they have no conscious recollection of having seen those features. In support of this theory, Jones and Jacoby demonstrated that the likelihood of conjunction memory errors in young adults was unaffected by manipulations such as distraction and response deadlines that are thought to selectively impair recollection while leaving familiarity intact. These results suggest that young adults have difficulty using recollection to reject conjunction items even in the absence of distraction or response deadlines (although taking special measures, such as warning young adults about the possibility of conjunction errors or presenting study items on multiple occasions, can lead to reduced acceptance of conjunction items; see, e.g., Lampinen, Odegard, \& Neuschatz, 2004).

This theory leads to the prediction that older adults should be no more susceptible to conjunction errors than are young adults. In particular, like distraction and response deadlines, aging is thought to impair recollection while leaving familiarity intact (see, e.g., Bastin \& Van der Linden, 2003; Jacoby, 1999). Young and older adults may thus receive equivalent feelings of familiarity for a conjunction stimulus. Moreover, given that young adults have difficulty using recollection to override these feelings of familiarity in order to reject a conjunction stimulus, young adults may be no less likely than older adults to falsely recognize such a stimulus. Consistent with this prediction, Jones and Jacoby (2005) have recently reported finding no age differences in the likelihood of conjunction memory errors when the method of Jones and Jacoby (2001) was used. These results thus suggest the possibility that there may not be age differences in the false recognition of a novel conjunction of a familiar actor and action.

\section{Overview of Experiments}

The present experiments were designed to measure the ability of young and older adults to remember which person performed each of a number of actions. To test this, we presented participants with brief video clips involving actors performing simple actions, such as waving a flag or peeling a banana. In a later session, we tested the participants on their memory for these video clips by presenting them with a series of video clips, some new and some previously seen, and asking them to identify which video clips they had seen in the first session of the experiment. The critical test items involved an actor seen in the first session of the experiment performing an action seen in the first session of the experiment, but this action had been performed by a different actor in the first session. The ability to distinguish these conjunction items from old items thus provided a measure of a participant's binding of actors with actions.

Experiment 1 involved presenting young and older adult participants with video clips depicting the actions of a small group of middle-aged female actors. The participants were later tested on their memory for these video clips, providing us with measures of the participants' memory for the actions that they saw, as well as their memory for which actor performed each of those actions. Middleaged actors were employed in this experiment because they were intermediate in age between the young and the older adult participants and, thus, would presumably not confer an advantage upon either age group in their ability to remember the actors. Experiment 2 involved presenting participants with the actions of a much larger group of female undergraduate students. This allowed us to test not only memory for actions, but also memory for actors, as well as 
the association of these two types of information. Finally, Experiment 3 tested whether the results of the first two experiments could be explained in terms of the detection of subtle differences in the way an action was performed by different actors. Thus, in addition to testing a participant's ability to bind actors with actions, a test of action memory was administered, allowing an examination of young and older adults' sensitivities to differences in the way an action was performed at encoding and at retrieval.

\section{EXPERIMENT 1}

\section{Method}

Participants. Seventy-six undergraduates $(M=20.00$ years, $S D=3.38$, range $=18-38$ years $)$ received course credit in general psychology classes at Florida Atlantic University for their participation. Thirty-eight older adults $(M=72.0$ years, $S D=6.17$, range $=$ $60-81$ years) were recruited from the community and received $\$ 10$ gift certificates to a local movie theater. Participant characteristics are reported in Table 1.

Stimuli. One hundred twenty video clips were filmed using a Hi8 camcorder. Each video clip involved a female actor performing a simple action (e.g., waving a flag or peeling a banana; example videos are available at the Psychonomic Society Archive of Norms, Stimuli, and Data, www.psychonomic.org/archive). There were six different actors ranging in age from 45 to 55 years, each of whom performed 20 different actions. All of the actions were performed while the actor sat at a desk in front of a neutral background. The video clips were then imported onto a Dell Dimension XPS R350 computer, using an ATI All-in-Wonder video card, and were edited using the Adobe Premiere 5.1 software package so that they ranged in duration from 2.1 to $4.0 \mathrm{sec}(M=3.3 \mathrm{sec})$.

Encoding lists were created by selecting 5 of the 20 actions performed by each of the six actors, yielding a total list length of 30 items involving 30 different actions. Two different encoding lists were created in this manner, with no overlap in the actions involved in the two lists. Two different recognition lists, each involving 90 video clips, were also constructed, one corresponding to each of the encoding lists. Thirty of these video clips, the old items, were identical to those in the encoding list. Thirty video clips, the new action items, involved an actor from the encoding list performing an action from the opposite encoding list. Finally, 30 video clips, the conjunction items, involved an actor from the encoding list performing an action from the encoding list, but this actor and action had never been paired in the encoding list. Each of the six actors was involved in five conjunction items, and the actions involved in these five conjunction items had been performed by five different actors at encoding.

Procedure. The participants were instructed that they were to view a number of video clips on the computer screen and that they would later be tested on their memory for the video clips. The 30 encoding events were then presented on 17-in. computer monitors

Table 1

Participant Characteristics in Experiment 1

\begin{tabular}{lrrrrrc}
\hline & \multicolumn{3}{l}{ Young Adults } & & \multicolumn{3}{c}{ Older Adults } & \\
\cline { 2 - 3 } Characteristic & \multicolumn{1}{c}{$M$} & $S D$ & & $M$ & $S D$ & $p$ \\
\hline Age & 20.00 & 3.38 & & 72.04 & 6.17 & $<.001$ \\
Education & 12.54 & 0.97 & & 13.16 & 3.23 & .13 \\
Health & 4.18 & 0.72 & & 3.79 & 1.02 & .02 \\
Medications & 0.34 & 0.76 & & 2.95 & 2.64 & $<.001$ \\
Vocabulary & 26.80 & 3.70 & & 33.45 & 3.87 & $<.001$ \\
\hline
\end{tabular}

Note $-p=$ probability level associated with comparison between young and older adults on a given variable. Education $=$ number of years of education. Health $=$ self-reported health on a scale of 1 (poor) to 5 (excellent). Medications $=$ number of prescription medications currently being taken . Vocabulary $=$ score out of 40 on the Shipley (1986) Vocabulary Test. using the Macromedia Director 6.5 software package. A different random order of presentation was used for each participant. At the end of each event, a white screen appeared containing a button labeled "Next Event." The participants clicked on this button with a computer mouse to view the next video clip.

After viewing the 30 encoding events, a demographics questionnaire was administered on the computer. The participants were asked to provide their date of birth, gender, racial and ethnic background, years of education, a rating of health status on a scale of 1 (poor) to 5 (excellent), the number of medications they were taking, whether or not they had a history of high blood pressure or cardiovascular disease, and whether they had any difficulty seeing the video clips.

After the demographics questionnaire, a vocabulary test was administered. Forty vocabulary words from the Shipley Institute of Living Scale (Shipley, 1986) were presented to the participants one at a time on the computer screen in capital letters. Underneath each target word, there were four buttons, each labeled by a different word. The participants were instructed to use the computer mouse to click on the button labeled by the word that was the most similar in meaning to the target word. After the vocabulary test, the first session of the experiment was complete, and the participants were invited to return again for their second appointment time.

Older adults and half of the young adults returned 1 week later to be tested on their memory for the video clips. The other half of the young adults returned 3 weeks later. The purpose of this longer retention interval for half of the young adults was to attempt to equate young and older adults on memory for the actions, so that age differences in the binding of actors and actions could be examined in the absence of age differences in memory for the actions themselves. The participants were instructed that they would be viewing a number of video clips and that they were to indicate whether they had seen each of these video clips in the first session of the experiment. The participants were warned that some of the video clips would involve a familiar action performed by an actor other than the one who had performed that action in the first session of the experiment. The participants were instructed that they should respond yes to a video clip only if an action was performed by the same actor who had performed that action in the first session of the experiment.

The 90 retrieval events were then presented. A different random order of presentation was used for each participant. At the end of each event, the question "Did you see this person perform this action in the first part of the experiment?" appeared against a white background, with two buttons labeled "yes" and "no" appearing beneath it. The participants used the computer mouse to click on the button corresponding to their answer. They then clicked on one of three buttons to indicate their confidence in their response, with one button labeled "just guessing," one labeled "pretty sure," and one labeled "absolutely sure."

Design. The independent variable in this experiment was participant group (young adults tested after a 1-week delay vs. young adults tested after a 3-week delay vs. older adults tested after a 1-week delay). Two dependent variables were examined in relation to this independent variable. One was discrimination of old items and conjunction items, providing a measure of binding ability. The only difference between these two types of items was that the old items involved a familiar pairing of a familiar actor and action, whereas the conjunction items involved a novel pairing of a familiar actor and action. Thus, discriminating between these two types of items required a participant to associate or bind together an action with the actor who performed that action. The second dependent variable was discrimination of old items and new action items, providing a more general measure of recognition ability (i.e., action memory).

\section{Results}

Discrimination performance was examined by analyzing receiver-operating characteristic (ROC) functions. An ROC function relates the proportion of hits to old items to the proportion of false alarms to new items at each of a number of levels of confidence, with the number of confidence 
levels typically ranging from 6 to 10 (Yonelinas, 1994). In order to construct a confidence scale with the desired properties, the participants' old/new recognition judgments were combined with their confidence ratings on a scale of 1 to 3 , yielding a 6-point rating scale (i.e., $1=$ absolutely sure old, $2=$ pretty sure old, $3=$ just guessing old, $4=$ just guessing new, $5=$ pretty sure new, and $6=$ absolutely sure new).

An ROC analysis of the ability to bind actors and actions was first conducted by computing an ROC function for each of the three groups of participants relating the mean proportion of hits to old items to the mean proportion of false alarms to conjunction items. These old-conjunction ROC functions are presented in the upper panel of Figure 1. In order to perform statistical comparisons on these functions, an individual ROC function was computed for each participant. The area under each participant's ROC function was then computed as a summary measure of discrimination performance (see Macmillan \& Creelman, 2005). A score of .5 on this summary measure would indicate no discrimination of old and conjunction items, with the ROC falling along the central diagonal. A score of 1.0, on the other hand, would indicate perfect discrimination. The mean and standard deviation of this summary measure from each of the three participant groups are presented in Table 2.

An ANOVA on this measure of discrimination of old and conjunction items revealed a significant effect of participant group $\left[F(2,111)=13.74, M S_{\mathrm{e}}=.008, p<.001, \eta_{\mathrm{p}}^{2}=.198\right]$. Tukey HSD tests revealed poorer discrimination in the older adults tested after a 1-week delay than in either the young adults tested after a 1-week delay $(q=7.38, p<.001)$ or the young adults tested after a 3-week delay $(q=4.26, p=$ $.009)$. There was also a trend toward greater discrimination in the young adults tested after a 1-week delay than in the young adults tested after a 3-week delay, although this trend only approached significance $(q=3.12, p=.075)$.

An ROC analysis of general recognition ability was also conducted by computing an ROC function for each of the three groups of participants relating the mean proportion of hits to old items to the mean proportion of false alarms to new action items. These ROC functions are presented in the lower panel of Figure 1, and the mean and standard deviation of the area under the ROC from each of the three participant groups are presented in Table 2. An ANOVA on this measure of discrimination of old and new action items revealed a significant effect of participant group $[F(2,111)=$ $\left.11.24, M S_{\mathrm{e}}=.10, p<.001, \eta_{\mathrm{p}}^{2}=.168\right]$. Tukey HSD tests revealed greater discrimination of old and new action items in the young adults tested after a 1-week delay than in either the young adults tested after a 3-week delay $(q=4.94, p=$ $.002)$ or the older adults tested after a 1-week delay $(q=$ $6.40, p<.001)$, whereas there was not a significant difference between the latter two groups $(q=1.46, p>.10)$.

\section{Discussion}

The results of Experiment 1 revealed that the older adults had greater difficulty than did the young adults at discriminating old items from conjunction items, in which a familiar actor performed an action that had, in fact, been performed by a different actor at encoding. Moreover, the older adults had greater difficulty than did the young adults at remember-
A

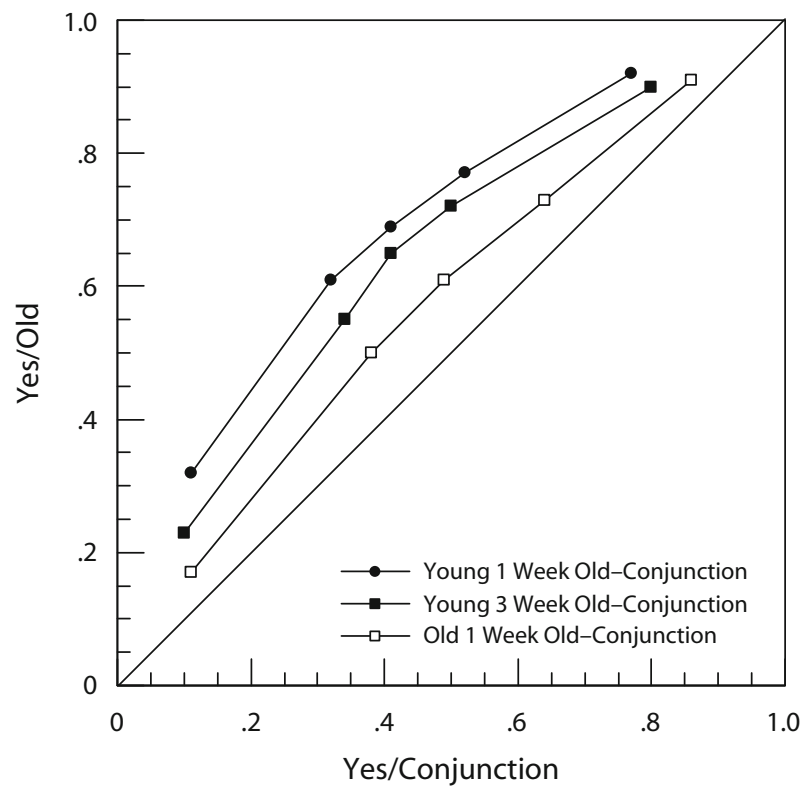

B

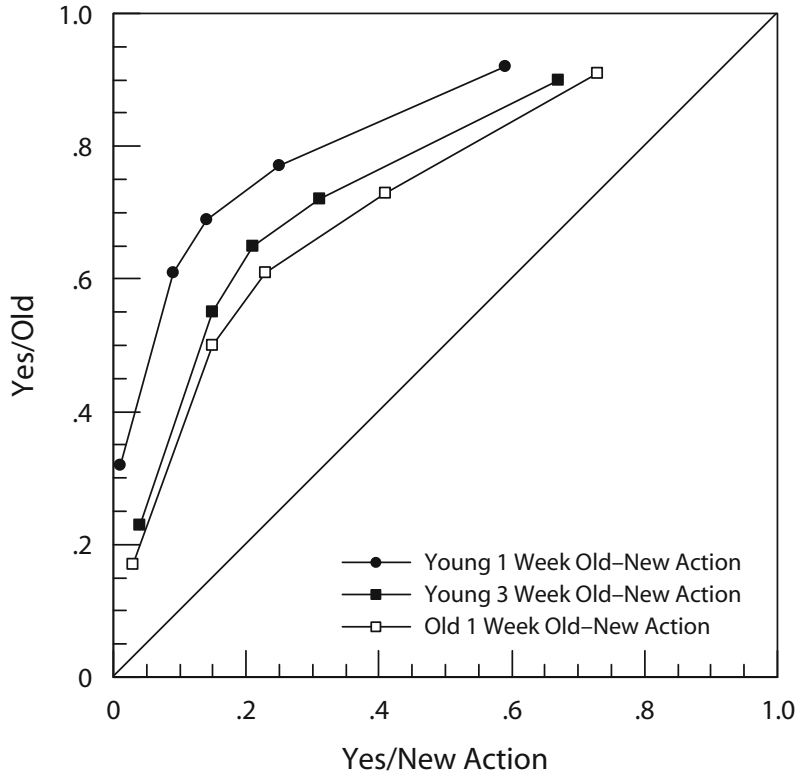

Figure 1. Receiver-operating characteristic functions relating confidence in responses to old items to confidence in responses to the two different types of new items (i.e., conjunction and new action items) in Experiment 1, in response to the question "Did you see this person perform this action in the first part of the experiment?" The first point in each function relates the probability of responding absolutely sure yes to old items and to new items. The second point relates the probability of responding either absolutely sure yes or pretty sure yes to old items and to new items. This same pattern continues for the remaining points on each function and the remaining confidence levels. (A) Relation of confidence in responses to old items to confidence in responses to conjunction items, providing a measure of the ability to bind actors with their actions in each participant group. (B) Relation of confidence in responses to old items to confidence in responses to new action items, providing a measure of more general recognition performance in each participant group. 
Table 2

Areas Under the Receiver-Operating Characteristic (ROC) Functions in Experiment 1

\begin{tabular}{llllll}
\hline & \multicolumn{2}{c}{$\begin{array}{c}\text { Old-Conjunction } \\
\text { ROC }\end{array}$} & & \multicolumn{2}{c}{$\begin{array}{c}\text { Old-New } \\
\text { ROC }\end{array}$} \\
\cline { 2 - 3 } \multicolumn{1}{c}{ Participant Group } & $M$ & $S D$ & & $M$ & $S D$ \\
\hline Young adults with a 1-week delay & .684 & .114 & & .839 & .077 \\
Young adults with a 3-week delay & .640 & .079 & & .757 & .129 \\
Older adults with a 1-week delay & .579 & .064 & & .733 & .091 \\
\hline
\end{tabular}

ing which actor performed an action even when memory for the actions themselves was equated by using a longer retention interval for young adults. This result suggests that older adults have a deficit in binding actors with their actions, consistent with an age-related associative or binding deficit (Chalfonte \& Johnson, 1996; Naveh-Benjamin, 2000).

There remains an alternative explanation for the results of Experiment 1, however, that does not involve an age-related associative or binding deficit. In particular, it remains possible that the older adults' poorer discrimination of old and conjunction items can be accounted for in terms of a failure to encode the actors in the events. The participants in Experiment 1 were never tested on their memory for the actors in the events. Thus, the older adults may simply have focused on the actions in the events and failed to encode the actors in the events. As a result, when the older adults were later presented with the recognition trials, they may have accepted an event as having been seen before as long as the action was familiar, regardless of the actor who performed that action. This would account for their reduced discrimination of the old items from the conjunction items, because both of these item types involved a familiar action. Thus, the older adults' poorer discrimination of old and conjunction items may reflect not a failure to bind actors with actions but, rather, a failure to encode the actors in the first place.

\section{EXPERIMENT 2}

Experiment 2 was designed to rule out this alternative hypothesis for the results of Experiment 1. To this end, a new set of video clips was created involving a large number of actors performing a large number of actions. The participants' memory for the actors could thus be tested in addition to their memory for the actions. In particular, in the encoding session of the experiment, the participants saw 30 different actors perform 30 different actions. At retrieval, the participants were tested with five different types of items. Old items were identical to the events seen at encoding. Conjunction items involved a familiar actor performing a familiar action that had been performed by a different actor at encoding. New action items involved a familiar actor performing an unfamiliar action. New actor items involved an unfamiliar actor performing a familiar action. Finally, new items involved an unfamiliar actor performing an unfamiliar action. If older adults' poorer discrimination of old and conjunction items reflects a failure to encode actors, older adults would be expected to exhibit a pattern of responding to new actor and new action items different from that exhibited by young adults. In particular, older adults would be expected to be much more likely to falsely recognize the new actor items than to falsely recognize the new action items, whereas young adults would be expected to show less of a difference in false recognition of the two types of items.

\section{Method}

Participants. Thirty-two undergraduates $(M=19.43$ years, $S D=1.05$, range $=18-23$ years) received course credit in general psychology classes at Florida Atlantic University for their participation. Thirty-two older adults $(M=69.38$ years, $S D=5.06$, range $=$ 61-78 years) were recruited from the community and received their choice of a t-shirt, tote bag, coffee mug, or candy bar. Participant characteristics are reported in Table 3.

Stimuli. Two hundred ten video clips were filmed using a Hi8 camcorder, ranging in duration from 2.9 to $4.0 \mathrm{sec}(M=3.9 \mathrm{sec})$. Each video clip involved a female actor performing a simple action. There were 90 different actors, ranging in age from 18 to 22 years. Each of sixty actors performed three actions, whereas each of the remaining 30 actors performed only a single action. All of the actions were performed while the actors sat at a desk in front of a neutral background.

Two encoding lists were created by selecting two unique sets of 30 events, each involving 30 different actors performing 30 different actions, with no overlap in either the actors or the actions involved in the two lists. Two additional encoding lists were created by combining 15 of the items from one encoding list with 15 of the items from the other encoding list, again with no overlap in either the actors or the actions involved in these two lists. Four different recognition lists were also constructed, one corresponding to each of the encoding lists. Each recognition list involved 150 video clips. Thirty of these video clips, the old items, were identical to those in the encoding list. Thirty video clips, the conjunction items, involved an actor from the encoding list performing an action from the encoding list, but this actor and action had never been paired in the encoding list. Thirty video clips, the new action items, involved an actor from the encoding list performing an action not contained within the encoding list. Thirty video clips, the new actor items, involved an actor not contained within the encoding list performing an action from the encoding list. Finally, 30 video clips, the new items, involved an actor not contained within the encoding list performing an action not contained within the encoding

Table 3

Participant Characteristics in Experiment 2

\begin{tabular}{|c|c|c|c|c|c|}
\hline \multirow[b]{2}{*}{ Characteristic } & \multicolumn{2}{|c|}{ Young Adults } & \multicolumn{2}{|c|}{ Older Adults } & \multirow[b]{2}{*}{$p$} \\
\hline & $M$ & $S D$ & $M$ & $S D$ & \\
\hline Age & 19.43 & 1.05 & 69.38 & 5.06 & $<.001$ \\
\hline Education & 12.44 & 0.81 & 16.91 & 2.78 & $<.001$ \\
\hline Health & 3.97 & 0.97 & 4.06 & 0.91 & .69 \\
\hline Medications & 0.25 & 0.51 & 3.84 & 2.84 & $<.001$ \\
\hline Vocabulary & 27.13 & 2.96 & 35.66 & 2.74 & $<.001$ \\
\hline
\end{tabular}

Note $-p=$ probability level associated with comparison between young and older adults on a given variable. Education = number of years of education. Health $=$ self-reported health on a scale of 1 (very poor) to $5($ very good $)$. Medications $=$ number of prescription medications currently being taken. Vocabulary $=$ score out of 40 on the Shipley (1986) Vocabulary Test. 
list. The recognition lists were counterbalanced so that a given video clip represented a conjunction item in one list, a new actor item in a second list, and a new action item in a third list and did not appear in the fourth list. The new items, on the other hand, were identical for all four recognition lists, with none of the actors or actions in these items appearing in any of the four encoding lists.

Procedure. The procedure was identical to that in Experiment 1 except that 150 , rather than 90 , recognition trials were presented and all of the young adults were tested with a 3-week delay between encoding and retrieval. All of the older adults were tested with a 1 -week delay, given that the use of these different retention intervals was successful in equating young and older adults on general recognition ability (i.e., action memory) in Experiment 1.

Design. The independent variable in this experiment was participant group (young vs. older adults). Three different dependent variables were examined in relation to this independent variable. One was discrimination of old and conjunction items, providing a measure of binding ability. The second was discrimination of old and new items, providing a measure of more general recognition ability. Finally, the third was discrimination of new actor and new action items, providing a measure of the relative attention to actors and actions in the two age groups.

\section{Results}

An analysis of the ability to bind actors and actions was first conducted by computing an ROC function for each group of participants relating the mean proportion of hits to old items to the mean proportion of false alarms to conjunction items. These old-conjunction ROC functions are depicted in the upper panel of Figure 2. The area under each participant's ROC function was again computed as a summary measure of discrimination performance. The mean and standard deviation of this summary measure from each of the two age groups are presented in Table 4 . A $t$ test on this measure revealed greater discrimination in the young adults than in the older adults $[t(62)=3.38$, $p=.001]$, providing further evidence for age differences in binding actors with actions.

An analysis of general recognition ability was also conducted by computing an ROC function for each group of participants relating the mean proportion of hits to old items to the mean proportion of false alarms to new items. These ROC functions are depicted in the lower panel of Figure 2, and the mean and standard deviation of the area under the ROC from each group of participants are presented in Table 4. A $t$ test on this measure of discrimination of old and new items failed to reveal a significant difference between the two participant groups $[t(62)=$ $0.29, p>.10]$, indicating comparable general recognition performance in the two age groups.

Finally, an analysis of the relative attention given to actors and actions in the two age groups was conducted by computing an ROC function for each group of participants relating confidence in responses to new actor items to confidence in responses to new action items. These ROC functions are depicted in the lower panel of Figure 2, and the mean and standard deviation of the area under the ROC from each group of participants are presented in Table 4. As can be seen in Figure 2, both groups exhibited ROC functions that were somewhat above the central diagonal, with a mean area under the ROC over all the participants that was significantly greater than $.5[t(63)=4.53, p<.001]$. These results indicate that both groups of participants were

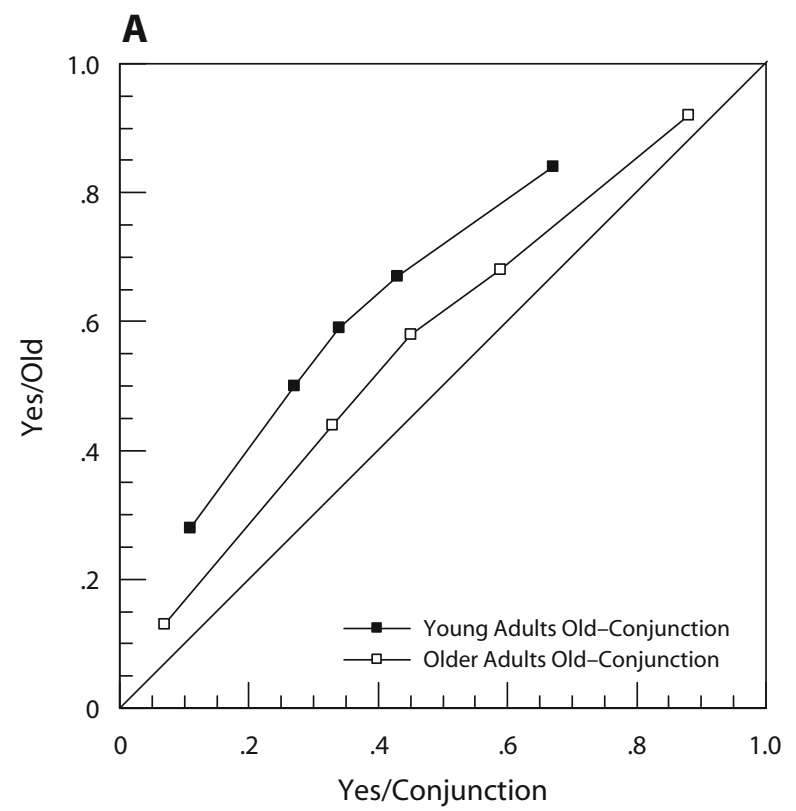

B

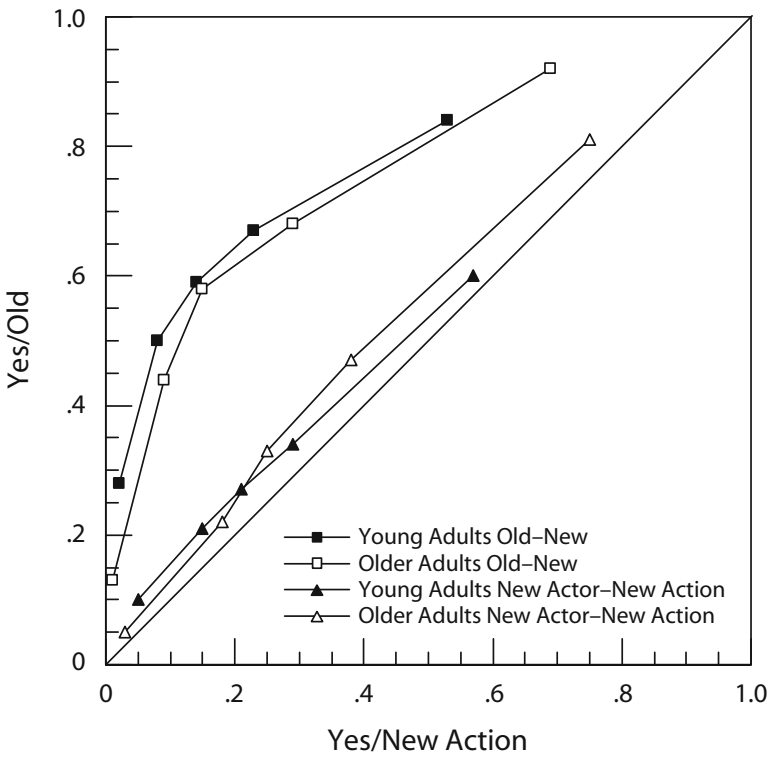

Figure 2. Receiver-operating characteristic functions relating confidence in responses to the different item types in Experiment 2. (A) Relation of confidence in responses to old items to confidence in responses to conjunction items, providing a measure of the ability to bind actors and actions in each age group. (B) Two measures of more general recognition performance in each age group. In particular, the upper functions in panel B relate confidence in responses to old items to confidence in responses to new items, providing a measure of old-new discrimination. The lower functions in panel $B$ relate confidence in responses to new actor items to confidence in responses to new action items, providing a measure of the relative attention given to actors and actions by each of the two age groups.

somewhat more likely to falsely recognize the new actor items than to falsely recognize the new action items. There was not a significant difference between the two age groups in the area under the new-actor-new-action ROC, however $[t(62)=1.63, p>.10]$, indicating similar patterns of atten- 
Table 4

Areas Under the Receiver-Operating Characteristic (ROC) Functions in Experiment 2

\begin{tabular}{llllll}
\hline \multirow{2}{*}{\multicolumn{1}{c}{ Function }} & \multicolumn{2}{c}{ Young Adults } & & \multicolumn{2}{c}{ Older Adults } \\
\cline { 2 - 3 } \cline { 6 - 7 } & $M$ & $S D$ & & $M$ & $S D$ \\
\hline Old-conjunction ROC & .654 & .084 & & .585 & .078 \\
Old-new ROC & .773 & .097 & & .766 & .080 \\
New-actor-new-action ROC & .530 & .081 & & .563 & .082 \\
\hline
\end{tabular}

tion to actors and actions in the two groups of participants. These results thus allow one to rule out the hypothesis that older adults' poorer discrimination of old and conjunction items reflects a failure to attend to the actors in the events.

\section{Discussion}

The results of Experiment 2 provide further evidence for an age-related deficit in the binding of actors and actions. Older adults again had greater difficulty discriminating old items from novel conjunctions of familiar actors and actions, even when the young and the older adults were equated on memory for the individual features of an event by using a longer retention interval for young adults. This combination of findings suggests that older adults' poorer discrimination of old and conjunction items cannot be accounted for in terms of a deficit in feature memory. These results instead suggest an age-related deficit in the binding of actors and actions.

\section{EXPERIMENT 3}

Experiment 3 was designed to rule out two alternative explanations for the results of Experiments 1 and 2. First, it is possible that the young adults' greater discrimination of old and conjunction items in Experiments 1 and 2 did not reflect stronger associations between an action and the actor who performed it but, rather, greater sensitivity to subtle differences in the way an action was performed by two different actors. Although care was taken to ensure that a given action was performed in as similar a manner as possible by two different actors, there were almost certainly still subtle differences in the way the action was performed by two different actors. Although the older adults tested after a 1-week delay performed just as well as the young adults tested after a 3-week delay at discriminating old items from new action items, the older adults may have had greater difficulty with the much more subtle discrimination between an item involving an action performed in exactly the same way as at encoding (i.e., an old item) and an item involving the same action performed in a slightly different manner (i.e., a conjunction item).

In order to test this alternative hypothesis, the participants in Experiment 3 were given not only a conjunction memory test, in which they were asked, "Did you see THIS PERSON PERFORM THIS ACTION in the first part of the experiment?" but also an action memory test, in which they were asked, "Did you see anyone perform THIS ACTION in the first part of the experiment?" Thus, the correct answer was $y e s$ to both the old and the conjunction items in the action memory test, because both of these types of items involved an action that had been seen at encoding. If participants are sensitive to subtle differences in the way an action is performed at encoding and retrieval, however, one would predict that they should be more likely to respond yes to the old items than to the conjunction items. In particular, because the actions portrayed in the conjunction items differed subtly in their perceptual details from the actions that had been seen at encoding, the participants may have received reduced feelings of familiarity when viewing the conjunction items (see, e.g., Koutstaal, 2003). If this alternative explanation for the results of Experiments 1 and 2 is correct, young adults would be expected to exhibit greater sensitivity to differences in the way an action was performed at encoding and at retrieval and, thus, show greater discrimination of old and conjunction items than do older adults in the action memory test, as well as in the conjunction memory test. If, on the other hand, the results of Experiments 1 and 2 reflect age differences in binding ability rather than action memory, young adults should show greater discrimination of old and conjunction items than do older adults only in the conjunction memory test.

A second alternative explanation for the results of Experiments 1 and 2 stems from the fact that the same actors and actions appeared in multiple test items. For example, the same action may have appeared in an old item, performed by the same actor who had performed that action at encoding, and later in a conjunction item, performed by a different actor. Although the actor appearing in a conjunction item had never previously been seen performing the action appearing in that item, it remains possible that the repetition over the course of the test trials of the actors and actions appearing in the conjunction items may have increased the familiarity of those items, inflating the false recognition of those items (see, e.g., Jennings \& Jacoby, 1997). To rule out this possibility, each actor and action appeared only once in the test trials in Experiment 3. Thus, if participants continued to exhibit a high rate of false recognition of the conjunction items, this would implicate exposure at encoding to the actors and actions appearing in those items as being responsible for that false recognition.

\section{Method}

Participants. Thirty-six undergraduates $(M=19.32$ years, $S D=$ 1.33 , range $=18-26$ years) received course credit in general psychology classes at Florida Atlantic University for their participation. Thirty-six older adults $(M=70.49$ years, $S D=6.09$, range $=$ 61-87 years) were recruited from newspaper ads and received a $\$ 20$ gift certificate to a local restaurant or movie theater. Participant characteristics are reported in Table 5.

Stimuli. One hundred fifty of the video clips used in Experiment 2 were employed in Experiment 3. Three sets of 40 video clips were used as encoding lists, involving a total of 60 different actors and 60 different actions. Each list comprised 40 of these 60 actors performing 40 of these 60 actions, although the pairings of actors and actions were unique to each list. Three different recognition lists were also constructed, one corresponding to each of the encoding lists. Each recognition list involved 90 video clips. Twenty of these video clips, the old items, were identical to items in the encoding list. Twenty video clips, the conjunction items, involved an actor from the encoding list performing an action from the encoding list, but this actor and action had never been paired in the encoding list. Finally, 50 video clips, the new items, involved an actor not con- 
tained within the encoding list performing an action not contained within the encoding list. The old items, conjunction items, and 20 of the new items were counterbalanced so that a given item equally often represented each of the three item types. The remaining 30 new items were identical for the three recognition lists. Unlike in Experiments 1 and 2, each actor and action appeared only once in a given retrieval list, thus removing any interference from the participants' having seen the same actor or action earlier in the retrieval list.

Procedure. The procedure for the encoding session was identical to that in Experiment 2, except that the participants viewed 40 encoding events, rather than 30. As in Experiment 2, the older adults returned 1 week later for the retrieval session, whereas the young adults returned 3 weeks later. Half of the participants in each group were initially given the same conjunction memory test that was employed in Experiments 1 and 2. In particular, these participants were instructed that after each video clip they would be asked the question "Did you see THIS PERSON PERFORM THIS ACTION in the first part of the experiment?" They were further instructed that they would sometimes see a familiar action performed by a familiar actor other than the one who had performed that action at encoding and that they should respond no to these items. Finally, they were instructed that there would be 30 trials in this part of the experiment and that the correct answer would be yes on 10 of these trials and no on the remaining 20 trials. The participants were then presented with 30 trials, 10 of which were old items (to which the correct answer was yes), 10 of which were conjunction items (to which the correct answer was no), and 10 of which were new items (to which the correct answer was no).

These same participants were later given the action memory test. The participants were instructed that after each video clip, they would be asked the question "Did you see anyone perform THIS ACTION in the first part of the experiment?" They were further instructed that they would sometimes see a familiar action performed by a familiar actor other than the one who had performed that action at encoding and that they should respond yes to these items. Finally, they were instructed that there would be 60 trials in this part of the experiment and that the correct answer would be yes in 20 of these trials and no in the remaining 40 trials. The participants were presented with 60 trials, 10 of which were old items (to which the correct answer was yes), 10 of which were conjunction items (to which the correct answer was yes), and 40 of which were new items (to which the correct answer was no).

The procedure for the other half of the participants was identical, except that the order of presentation of the two tasks was reversed. In addition to varying the order of the two retrieval tasks, the assignment of items to the conjunction memory and action memory tests was also varied across participants. In particular, half of the items of each type were assigned to the conjunction memory test and the other half were assigned to the action memory test for half of the participants, whereas these assignments were reversed for the other half of the participants.

Design. There were three independent variables in this experiment. One was participant group (young vs. older adults), manipulated between subjects. A second independent variable was test type

Table 5

Participant Characteristics in Experiment 3

\begin{tabular}{|c|c|c|c|c|c|}
\hline \multirow[b]{2}{*}{ Characteristic } & \multicolumn{2}{|c|}{ Young Adults } & \multicolumn{2}{|c|}{ Older Adults } & \multirow[b]{2}{*}{$p$} \\
\hline & $M$ & $S D$ & $M$ & $S D$ & \\
\hline Age & 19.32 & 1.33 & 70.49 & 6.09 & $<.001$ \\
\hline Education & 12.25 & 1.62 & 15.22 & 2.28 & $<.001$ \\
\hline Health & 4.08 & 0.84 & 4.22 & 0.72 & .46 \\
\hline Medications & 0.22 & 0.54 & 2.72 & 3.45 & $<.001$ \\
\hline Vocabulary & 27.31 & 3.31 & 35.47 & 3.25 & $<.001$ \\
\hline
\end{tabular}

Notes $-p=$ probability level associated with comparison between young and older adults on a given variable. Education $=$ number of years of education. Health $=$ self-reported health on a scale of 1 (poor) to 5 (excellent). Medications $=$ number of prescription medications currently being taken . Vocabulary $=$ score out of 40 on the Shipley (1986) Vocabulary Test. (action vs. conjunction), manipulated within subjects. Finally, the third independent variable was test order (action first vs. conjunction first), manipulated between subjects. Two different dependent variables were examined in relation to these independent variables. One was discrimination of old and conjunction items, providing a measure of binding ability. The second was discrimination of old and new items, providing a measure of more general recognition ability.

\section{Results}

Initial analyses of discrimination ability with participant group, test type, and test order as independent variables revealed a significant interaction of test type and test order on discrimination of old and new items $[F(1,68)=10.66$, $\left.M S_{\mathrm{e}}=.008, p=.002, \eta_{\mathrm{p}}^{2}=.136\right]$, as well as an interaction of participant group and test order on discrimination of old and conjunction items that approached significance $\left[F(1,68)=2.98, M S_{\mathrm{e}}=.016, p=.089, \eta_{\mathrm{p}}^{2}=.042\right]$. These interactions indicate that the order in which the conjunction and action memory tests were administered influenced discrimination performance in those tests. Thus, in order to obtain uncontaminated measures of conjunction and action memory in the two age groups, analysis was limited to the first test type (i.e., action or conjunction) administered to a given participant. Test type was thus treated as a betweensubjects variable in subsequent analyses, with half of the participants in each age group assigned to the conjunction memory test and half assigned to the action memory test.

An ROC analysis of binding ability was conducted by computing ROC functions for each group of participants relating confidence in responses to old items to confidence in responses to conjunction items. Separate oldconjunction ROC functions were computed for the action memory test and the conjunction memory test, because the participants were instructed to respond yes to conjunction items in the action memory test but no to conjunction items in the conjunction memory test. The ROC functions relating the two age groups' responses to old items and conjunction items in the conjunction memory test are depicted in the top panel of Figure 3, whereas the corresponding ROC functions for the action memory test are depicted in the middle panel of Figure 3. The area under each participant's ROC function was again computed as a summary measure of discrimination performance. The mean and standard deviation of this summary measure from each of the two age groups for both the conjunction and the action memory test are presented in Table 6 .

An ANOVA on this measure of discrimination of old and conjunction items revealed a significant main effect of participant group $\left[F(1,68)=4.29, M S_{\mathrm{e}}=.013, p=.042\right.$, $\left.\eta_{\mathrm{p}}^{2}=.059\right]$. This main effect, however, was moderated by a significant interaction of participant group and test type $\left[F(1,68)=6.56, M S_{\mathrm{e}}=.013, p=.013, \eta_{\mathrm{p}}^{2}=.088\right]$. An analysis of simple main effects revealed that in the conjunction memory test, the young adults exhibited significantly greater discrimination of old and conjunction items than did the older adults $[t(34)=3.26, p=.003]$, in replication of Experiments 1 and 2. In the action memory test, on the other hand, the two groups did not significantly differ in discrimination of old and conjunction items $[t(34)=0.35$, $p>.10]$. Both groups did, in fact, respond more positively to old items than to conjunction items in the action memory 
A

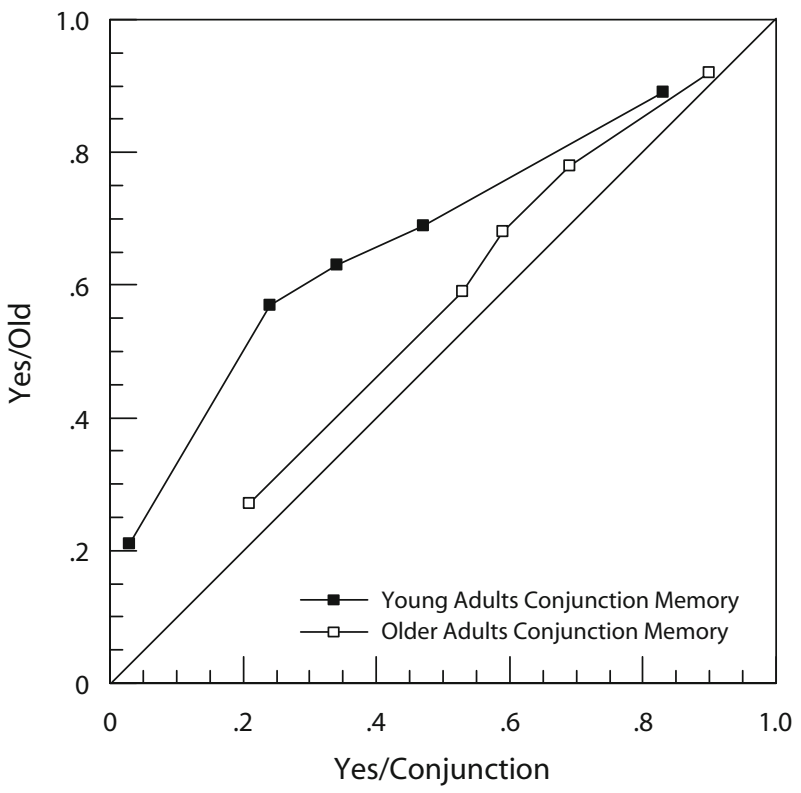

B

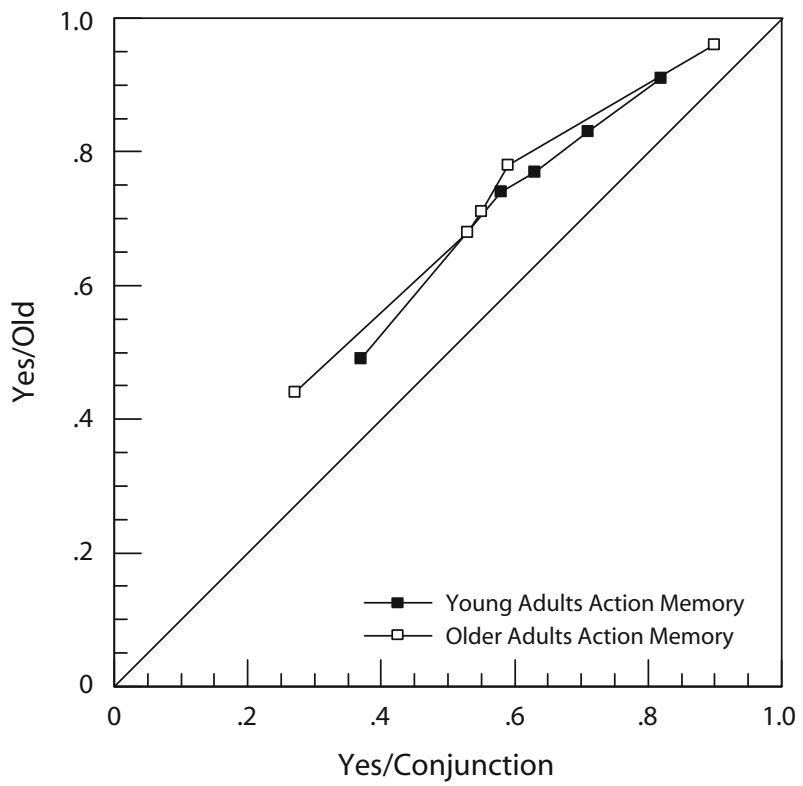

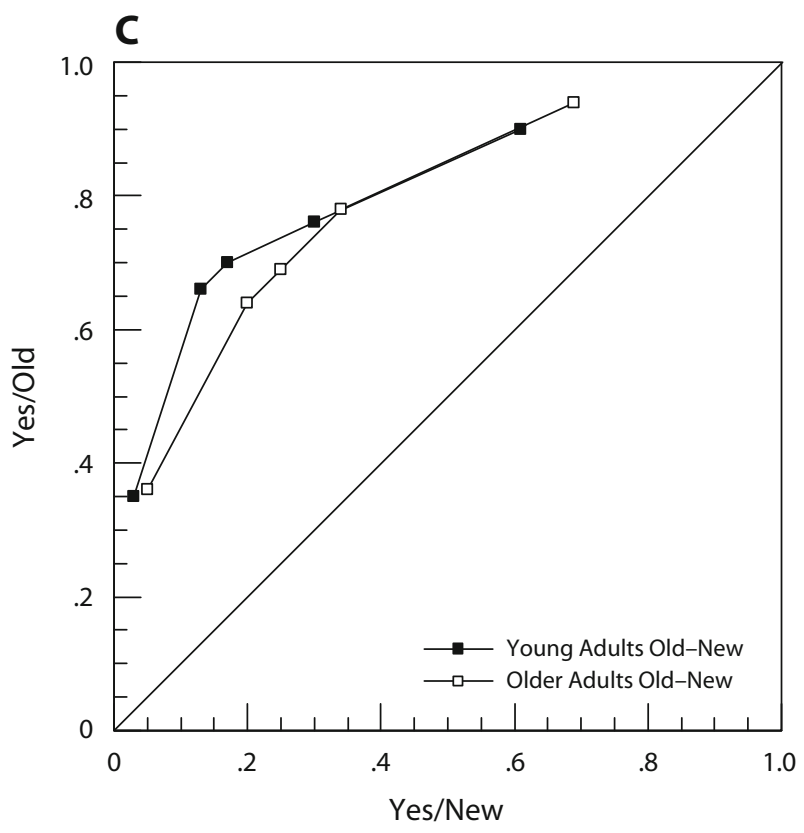

Figure 3. Receiver-operating characteristic functions relating confidence in responses to old items to confidence in responses to the two different types of new items (i.e., conjunction and new items) in Experiment 3. (A) Relation of confidence in responses to old items to confidence in responses to conjunction items in the conjunction memory test, providing a measure of the ability to bind actors with their actions in each age group. (B) Relation of confidence in responses to old items to confidence in responses to conjunction items in the action memory test, providing a measure of sensitivity in each age group to differences in the way an action was performed by two different actors at encoding and at retrieval. (C) Relation of confidence in responses to old items to confidence in responses to new items, providing an indication of old-new discrimination in the two age groups.

test, despite the instruction to treat them equivalently. In particular, the mean area under the old-conjunction ROC over all the participants who were assigned to the action memory condition was significantly greater than $.5[t(35)=5.67$, $p<.001]$. This discrimination of old and conjunction items in the action memory test was nearly identical in the two groups, however. These results thus provide no evidence for the hypothesis that the young adults were more sensitive than the older adults to differences in the way an action was performed at encoding and at retrieval.

An analysis of general recognition ability was also conducted by computing an ROC function for each age group relating the mean proportion of hits to old items to the mean proportion of false alarms to new items. The results 
Table 6

Areas Under the Receiver-Operating Characteristic (ROC) Functions in Experiment 3

\begin{tabular}{lccccc}
\hline & \multicolumn{2}{c}{ Young Adults } & & \multicolumn{2}{c}{ Older Adults } \\
\cline { 2 - 3 } \multicolumn{1}{c}{ Function } & $M$ & $S D$ & & $M$ & $S D$ \\
\hline Conjunction test old-conjunction ROC & .678 & .111 & & .555 & .115 \\
Action test old-conjunction ROC & .598 & .119 & & .611 & .105 \\
Old-new ROC & .815 & .117 & .785 & .111 \\
\hline
\end{tabular}

of the conjunction condition and the action condition were aggregated in this analysis because both groups were instructed to respond yes to the old items and no to the new items. These ROC functions are depicted in the bottom panel of Figure 3, and the mean and standard deviation of the area under the ROC from each group of participants are presented in Table 6. A $t$ test on this measure of discrimination of old and new items failed to reveal a significant difference between the two participant groups $[t(70)=1.26$, $p>.10]$, indicating comparable general recognition performance in the two age groups. These results thus suggest that young adults' greater discrimination of old and conjunction items in the conjunction memory test cannot be explained in terms of general recognition performance.

\section{Discussion}

The results of Experiment 3 provide further evidence of age differences in the binding of actors and actions. Older adults again had greater difficulty discriminating old items from novel conjunctions of familiar actors and actions, even when general recognition performance was equated in the two age groups by using a longer retention interval for the young adults. Experiment 3 also demonstrated equivalent memory for actions in the young and the older adults, arguing against the hypothesis that the older adults' poorer discrimination of old and conjunction items in the conjunction memory test was a result of reduced sensitivity to differences in the way an action was performed at encoding and at retrieval. Finally, the older adults had greater difficulty than did the young adults at discriminating old items from novel conjunctions of familiar actors and actions, even when those actors and actions had been encountered only in the encoding list and had not appeared previously in the recognition list, implicating exposure at encoding as being responsible for false recognition of the conjunction items.

\section{GENERAL DISCUSSION}

The present experiments provide evidence that older adults have greater difficulty than young adults at remembering which actions were performed by which actors. In particular, the results of Experiment 1 revealed that the older adults had greater difficulty than did the young adults at discriminating old events from events involving a familiar action performed by a familiar actor other than the one who had performed that action at encoding. This was true even when memory for the actions themselves was equated by using a longer retention interval for the young adults. Experiment 2 revealed this same effect even when the young and the older adults were equated on memory for both of the basic features of the events (i.e., actors and actions), again by using a longer retention interval for the young adults. This result suggests that older adults' poorer discrimination of old items from novel conjunctions of familiar actors and actions reflects a difficulty in the binding of features, rather than a difficulty in remembering the features themselves. Finally, Experiment 3 demonstrated that the young and the older adults were equally sensitive to differences in the way an action was performed at encoding and at retrieval in an action memory test, suggesting that the results of the previous experiments could not be explained in terms of the detection of subtle differences in the way an action was performed by different actors.

\section{Adult Age Differences in Memory Performance}

These results are consistent with prior results showing an age-related impairment in binding in memory (e.g., Chalftonte \& Johnson, 1996; Naveh-Benjamin, 2000) associated with declines in hippocampal and prefrontal cortical functioning (Mitchell et al., 2000). They also extend previous results showing an age-related deficit in source monitoring (e.g., Ferguson et al., 1992; Hashtroudi et al., 1989; Johnson et al., 1995), demonstrating that these deficits apply not only to speech acts, but also to other types of perceived actions. Finally, the present results are consistent with prior results suggesting greater reliance on familiarity and reduced reliance on recollection with advanced age (e.g., Bastin \& Van der Linden, 2003; Jacoby, 1999).

Age differences in the discrimination of old and conjunction items occurred not only in Experiments 1 and 2, in which the actors and actions were repeated over the recognition trials, but also in Experiment 3, in which each actor and action appeared only once at recognition. This result allows one to rule out the possibility that older adults' poorer discrimination of old and conjunction items simply reflects familiarity for the actor and action appearing in a conjunction item as a result of having seen that actor and action on multiple occasions during the test procedure.

Older adults' discrimination of old and conjunction items was, in fact, ordinally greater in Experiment 2, in which actors and actions repeated over test items, than in Experiment 3, in which each actor and action appeared only once at test, even though the same stimuli were used in these experiments. A possible explanation for this trend is that although older adults may have had difficulty rejecting the conjunction items on the basis of recollection of the study items that they had seen 1 week earlier, the older adults in Experiment 2 may have been able to recollect prior test trials that they had seen minutes earlier. Thus, if an older adult had recently accepted an old item, on the basis of either recollection or familiarity, and was then presented with a conjunction item involving the same actor who had appeared in that old item now performing a different action, the older adult might have been able to use recollection of the prior old item to reject the conjunction item. In particular, the older adult might reason that if he or she saw this actor performing the action depicted in the old item, this same actor could not have also been seen performing the action depicted in the conjunction item. 
This route to successful rejection of the conjunction items was not available in Experiment 3, because there was no overlap in the test items in this experiment and, thus, each test item had to be evaluated independently.

The young adults in Experiment 2 would also be expected to benefit in this manner from repetition of the actors and actions over test items, but this strategy for rejecting the conjunction items may have been less important for the young adults than for the older adults, because the young adults were more successful at rejecting the conjunction items on the basis of recollection of the study items. If this explanation is correct, it is possible that our estimates of age differences in the likelihood of conjunction errors observed in Experiments 1 and 2 may actually be somewhat conservative, as compared with a situation in which stimulus features are not repeated over test items.

\section{Relation to Findings on Conjunction Memory and Associative Recognition}

The present results differ from prior results by Jones and Jacoby (2005) using the conjunction memory paradigm with compound word stimuli. In particular, Jones and Jacoby found no evidence for age differences in conjunction memory errors unless special measures were taken, such as the repeated presentation of encoding items and the provision of diagnostic cues as to source. In contrast, the present research revealed age differences in the false recognition of a novel conjunction of a familiar actor and action, even in the absence of such measures.

Although the present results differ from the results of Jones and Jacoby (2005), they are quite consistent with results from a closely related paradigm - namely, the associative recognition paradigm, in which memory for pairs of words is tested (e.g., Kelley \& Wixted, 2001). Unlike the conjunction memory paradigm, studies of associative recognition have revealed effects of age, distraction, and response deadlines on the likelihood of false recognition of a conjunction stimulus involving two familiar words that did not appear together at encoding (Castel \& Craik, 2003; Light, Patterson, Chung, \& Healy, 2004).

The key feature that distinguishes the research of Jones and Jacoby $(2001,2005)$ from the present research, as well as from studies employing the associative recognition paradigm, may involve the extent to which a conjunction stimulus overlaps in meaning with the parent study items from which it was generated. As was pointed out by Jones and Jacoby (2001), a compound word stimulus, such as blackbird, is not closely related in meaning to either blackmail or jailbird. In particular, blackmail is not black, and a jailbird is not a bird. Thus, even young adults, in the absence of distraction or response pressure, may be unlikely to be able to use a conjunction item as a retrieval cue to recollect one of its parent study items. Because performance is, instead, driven by familiarity, manipulations such as age, distraction, or response pressure have no effect.

In contrast, in the associative recognition paradigm, each of the words in a word pair has an independent meaning that is preserved to some extent despite variations in context, particularly in the typical case in which those words are nouns (Kersten \& Earles, 2004). The mean- ing conveyed by a novel pairing of two familiar stimulus words thus overlaps to some extent with the meanings of the parent items in which those two stimulus words appeared at encoding. Because of this overlap in meaning, a word from a test pair may make a good retrieval cue for a study item involving that same word, allowing participants to reject a test item if they can recollect one of the words in that item having been paired with a different word at study. Consistent with this account, Odegard, Lampinen, and Toglia (2005) have provided evidence that young adults are able to use recollection of study items to reject conjunction items in a conjunction memory task similar to that employed by Jones and Jacoby (2001), but only when a conjunction word is semantically related to its parent items on the study list. The overlap in meaning between test and study items is thus crucial in determining whether young adults can use recollection to reject a conjunction item and, thus, whether there are age differences in a conjunction memory task.

The present results thus suggest that a particular pairing of an actor with an action is more similar to a word pair in the associative recognition paradigm than to a compound word in the conjunction memory paradigm. In particular, a novel conjunction of a familiar actor and action may make a good retrieval cue for other actions performed by that same actor or for the same action performed by other actors. Manipulations that decrease recollection while leaving familiarity intact, such as age, distraction, and response deadlines, would thus be expected to increase the likelihood that a novel conjunction of a familiar actor and action will be recognized.

\section{Relation to Theories of Unconscious Transference}

Although the stimuli employed in the present research were quite benign and ordinary, the present results may provide some insight into a phenomenon in the eyewitness testimony literature known as unconscious transference. Unconscious transference occurs when an eyewitness associates a familiar but innocent person with the actions of a perpetrator of a crime (see, e.g., E. Brown, Deffenbacher, \& Sturgill, 1977; Buckhout, 1974; Loftus, 1976; Perfect \& Harris, 2003; Read, Tollestrup, Hammersley, McFadzen, \& Christensen, 1990; Ross, Ceci, Dunning, \& Toglia, 1994). Thus, similar to binding errors in the present research, an eyewitness may correctly remember having encountered the innocent person and may correctly remember the criminal actions that were performed but may incorrectly associate the two, leading the eyewitness to believe that the innocent person has committed those criminal actions.

The present results suggest that it may be possible to explain unconscious transference in terms of the same basic memory mechanisms that are involved in binding errors in memory for compound words or word pairs. In particular, unconscious transference may reflect the familiarity of the innocent person and of the criminal actions, in the absence of recollection of the contexts in which that person and those actions were actually encountered. The predictions of this theory differ from those of the theory of unconscious transference proposed by Ross et al. (1994). 
They proposed that unconscious transference occurs when an eyewitness incorrectly concludes that a perpetrator encountered at a crime scene and an innocent person seen in a different context are actually the same person. Thus, an eyewitness may later remember having seen the innocent person commit the crime. It follows from this theory that a perpetrator and an innocent person must be similar enough in appearance to be confusable with one another.

It would appear to be easier to explain the present results in terms of binding errors than in terms of the confusability of the actors. The actors in Experiment 1 were no more similar in appearance than are individuals in any randomly selected group of middle-aged women, and thus it is unlikely that the participants believed that two of these actors were the same person. Moreover, the results of Experiment 2 revealed that the participants were better at remembering the actors that they had seen than they were at remembering which actor performed an action. These results suggest that confusability may not be the only mechanism underlying unconscious transference.

The theory of Ross et al. (1994) was proposed as an explanation for unconscious transference in a criminal setting, however, and it remains to be seen whether the present results will generalize to such a setting. It is possible that a criminal action is sufficiently distinct from ordinary actions that binding errors rarely occur in this context, and thus, confusability may indeed be the most likely explanation for unconscious transference in a criminal setting. Many of the actions that eyewitnesses are asked to testify about, however, may have appeared to be quite benign at the time (e.g., who was talking to whom or who was shredding documents) and only later became significant in a criminal case. Thus, binding errors may be a factor in a courtroom setting, even if not in cases involving emotionally charged actions, such as rapes and murders.

\section{Conclusions}

The present research provides evidence that older adults are more susceptible than young adults to errors in the binding of actors and actions. This, no doubt, has implications for the everyday social functioning of older adults. For example, older adults may have difficulty remembering who has already listened to a joke or a story, leading them to repeat that same information to the same individual (see, e.g., Koriat, Ben-Zur, \& Sheffer, 1988). Binding errors may also contribute to inaccuracies in eyewitness testimony. In particular, older eyewitnesses may be more likely than young eyewitnesses to associate a criminal act with an innocent person encountered in a different context (see, e.g., Perfect \& Harris, 2003). The present results revealed that even young adults are quite susceptible to errors in the binding of actors with actions, however. Binding errors may thus be a factor in memory for events regardless of the age of the person witnessing those events.

\section{AUTHOR NOTE}

Portions of this research were presented as a poster at the 44th Annual Meeting of the Psychonomic Society, Vancouver, November 2003, and as a spoken paper at the Tenth Biennial Meeting of the Cognitive Aging Conference, Atlanta, April 2004. This research was supported by
National Institute on Aging Grant R15-AG23526 and by a New Project Development Award from Florida Atlantic University. We thank David Bjorklund, Mark Faust, and Howard Hock for helpful suggestions regarding this research. We also thank Emily Allard, Derek Bagshaw, Samantha Kane, Elissa Klein, Genny Moss, Erik Pettersson, and Annemarie Phelan for their help in filming the video clips for Experiments 2 and 3. Finally, we thank Michelle Alvo, Erinn Beck, Don Bertke, Danielle Boutte, Melissa Bowen, Ariana Bowman, Jessica Bronner, Rayne Fischer, Farrin Jonas, Mary Slusarczyk, Tory Spokane, Beni Tsurumi, Jessica Wassung, and Erin Zeh for their help in running the experiments. Correspondence concerning this article should be addressed to A. W. Kersten, Department of Psychology, Florida Atlantic University, Boca Raton, FL 33431-0991 (e-mail: akersten@fau.edu).

\section{REFERENCES}

BASTIN, C., \& VAN DER Linden, M. (2003). The contribution of recollection and familiarity to recognition memory: A study of the effects of test format and aging. Neuropsychology, 17, 14-24.

BAYEN, U. J. (1999). Aging and source monitoring of characters in literary texts. Aging, Neuropsychology, \& Cognition, 6, 187-200.

Bayen, U. J., \& Murnane, K. (1996). Aging and the use of perceptual and temporal information in source memory tasks. Psychology \& Aging, 11, 293-303.

Brown, A. S., Jones, E. M., \& Davis, T. L. (1995). Age differences in conversational source monitoring. Psychology \& Aging, 10, 111-122.

Brown, E., Deffenbacher, K., \& Sturgill, W. (1977). Memory for faces and the circumstances of encounter. Journal of Applied Psychology, 62, 311-318.

BuckHout, R. (1974). Eyewitness testimony. Scientific American, 231, 23-31.

Cabeza, R. (2006). Prefrontal and medial temporal lobe contributions to relational memory in young and older adults. In H. D. Zimmer, A. Mecklinger, \& U. Lindenberger (Eds.), Handbook of binding and memory: Perspectives from cognitive neuroscience (pp. 595-626). Oxford: Oxford University Press.

Castel, A. D., \& Craik, F. I. M. (2003). The effects of aging and divided attention on memory for item and associative information. Psychology \& Aging, 18, 873-885.

Chalfonte, B. L., \& Johnson, M. K. (1996). Feature memory and binding in young and older adults. Memory \& Cognition, 24, 403-416.

Cutting, J. E., \& Kozlowski, L. T. (1977). Recognizing friends by their walk: Gait perception without familiarity cues. Bulletin of the Psychonomic Society, 9, 353-356.

Davis, H. P., \& Bernstein, P. A. (1992). Age-related changes in explicit and implicit memory. In L. R. Squire \& N. Butters (Eds.), Neuropsychology of memory (2nd ed., pp. 249-261). New York: Guilford.

EICHENBAUM, H., \& BUNSEY, M. (1995). On the binding of associations in memory: Clues from studies on the role of the hippocampal region in paired-associate learning. Current Directions in Psychological Science, 4, 19-23.

Ferguson, S. A., Hashtroudi, S., \& Johnson, M. K. (1992). Age differences in using source-relevant cues. Psychology \& Aging, 7, 443-452.

Giovanello, K. S., Schnyer, D. M., \& Verfaellie, M. (2004). A critical role for the anterior hippocampus in relational memory: Evidence from an fMRI study comparing associative and item recognition. Hippocampus, 14, 5-8.

GLISKY, E. L., RUBIN, S. R., \& DAVIDSON, P. S. R. (2001). Source memory in older adults: An encoding or retrieval problem? Journal of Experimental Psychology: Learning, Memory, \& Cognition, 27, 1131-1146.

GLuCK, M., \& MYeRs, C. (2001). Gateway to memory: An introduction to neural network modeling of the hippocampus and learning. Cambridge, MA: MIT Press.

Hashtroudi, S., Johnson, M. K., \& Chrosniak, L. D. (1989). Aging and source monitoring. Psychology \& Aging, 4, 106-112.

Henkel, L. A., Johnson, M. K., \& De Leonardis, D. M. (1998). Aging and source monitoring: Cognitive processes and neuropsychological correlates. Journal of Experimental Psychology: General, 127, 251-268.

JACOBY, L. L. (1999). Ironic effects of repetition: Measuring age-related differences in memory. Journal of Experimental Psychology: Learning, Memory, \& Cognition, 25, 3-22. 
JENNINGS, J. M., \& JACOBY, L. L. (1997). An opposition procedure for detecting age-related deficits in recollection: Telling effects of repetition. Psychology \& Aging, 12, 352-361.

Johnson, M. K., De Leonardis, D. M., Hashtroudi, S., \& Ferguson, S. A. (1995). Aging and single versus multiple cues in source monitoring. Psychology \& Aging, 10, 507-517.

Johnson, M. K., Hashtroudi, S., \& Lindsay, D. S. (1993). Source monitoring. Psychological Bulletin, 114, 3-28.

JoNES, T. C., \& JACOBY, L. L. (2001). Feature and conjunction errors in recognition memory: Evidence for dual-process theory. Journal of Memory \& Language, 45, 82-102.

Jones, T. C., \& JACOBY, L. L. (2005). Conjunction errors in recognition memory: Modality-free errors for older adults but not for young adults. Acta Psychologica, 120, 55-73.

Kelley, R., \& WiXTED, J. T. (2001). On the nature of associative information in recognition memory. Journal of Experimental Psychology: Learning, Memory, \& Cognition, 27, 701-722.

Kersten, A. W., \& Earles, J. L. (2004). Semantic context influences memory for verbs more than memory for nouns. Memory \& Cognition, 32, 198-211.

Koriat, A., Ben-Zur, H., \& Sheffer, D. (1988). Telling the same story twice: Output monitoring and age. Journal of Memory \& Language, 27, 23-39.

KoutstaAL, W. (2003). Older adults encode—-but do not always useperceptual details: Intentional versus unintentional effects of detail on memory judgments. Psychological Science, 14, 189-193.

Kroll, N. E. A., Knight, R. T., Metcalfe, J., Wolf, E. S., \& TulvING, E. (1996). Cohesion failure as a source of memory illusions. Journal of Memory \& Language, 35, 176-196.

Lampinen, J. M., Odegard, T. N., \& Neuschatz, J. S. (2004). Robust recollection rejection in the memory conjunction paradigm. Journal of Experimental Psychology: Learning, Memory, \& Cognition, 30, 332-342.

Light, L. L., Patterson, M. M., Chung, C., \& Healy, M. R. (2004). Effects of repetition and response deadline on associative recognition in young and older adults. Memory \& Cognition, 32, 1182-1193.

Loftus, E. F. (1976). Unconscious transference. Law \& Psychology Review, 2, 93-98.

Macmillan, N. A., \& Creelman, C.D. (2005). Detection theory: A user's guide (2nd ed.). Mahwah, NJ: Erlbaum.

Mitchell, K. J., Johnson, M. K., Raye, C. L., \& D'Esposito, M. D. (2000). fMRI evidence of age-related hippocampal dysfunction in feature binding in working memory. Cognitive Brain Research, 10, 197-206.

Naveh-Benjamin, M. (2000). Adult age differences in memory performance: Tests of an associative deficit hypothesis. Journal of Experimental Psychology: Learning, Memory, \& Cognition, 26, 1170-1187.

Naveh-Benjamin, M., Hussain, Z., Guez, J., \& Bar-On, M. (2003). Adult age differences in episodic memory: Further support for an associative-deficit hypothesis. Journal of Experimental Psychology: Learning, Memory, \& Cognition, 29, 826-837.

Odegard, T. N., Lampinen, J. M., \& Toglia, M. P. (2005). Meaning's moderating effect on recollection rejection. Journal of Memory \& Language, 53, 416-429.

O'Reilly, R. C., \& Rudy, J. W. (2001). Conjunctive representations in learning and memory: Principles of cortical and hippocampal function. Psychological Review, 108, 311-345.

Perfect, T. J., \& Harris, L. J. (2003). Adult age differences in unconscious transference: Source confusion or identity blending? Memory \& Cognition, 31, 570-580.

Prabhakaran, V., Narayanan, K., Zhao, Z., \& Gabrieli, J. D. E. (2000). Integration of diverse information in working memory within the frontal lobe. Nature Neuroscience, 3, 85-90.

RAhHAL, T. A., MAY, C. P., \& HAsher, L. (2002). Truth and character: Sources that older adults can remember. Psychological Science, 13, 101-105.

RAZ, N. (2000). Aging of the brain and its impact on cognitive performance: Integration of structural and functional findings. In F. I. M. Craik \& T. A. Salthouse (Eds.), The handbook of aging and cognition (2nd ed., pp. 1-90). Mahwah, NJ: Erlbaum.
Raz, N., Rodrigue, K. M., Head, D., Kennedy, K. M., \& Acker, J. D. (2004). Differential aging of the medial temporal lobe: A study of a five-year change. Neurology, 62, 433-438.

Read, J. D., Tollestrup, P., Hammersley, R., McFadzen, E., \& Christensen, A. (1990). The unconscious transference effect: Are innocent bystanders ever misidentified? Applied Cognitive Psychology, 4, 3-31.

Reinitz, M. T., Verfaellie, M., \& Milberg, W. P. (1996). Memory conjunction errors in normal and amnesic participants. Journal of Memory \& Language, 35, 286-299.

Ross, D. F., Ceci, S. J., Dunning, D., \& Toglia, M. P. (1994). Unconscious transference and mistaken identity when a witness misidentifies a familiar but innocent person. Journal of Applied Psychology, 79, 918-930.

Schacter, D. L., Kasziniak, A. W., Kinlstrom, J. F., \& Valdiserri, M. (1991). The relation between source memory and aging. Psychology \& Aging, 6, 559-568.

Selkoe, D. J. (1992). Aging brain, aging mind. Scientific American, 267, 135-142.

ShiPLey, W. C. (1986). Shipley Institute of Living Scale. Los Angeles: Western Psychological Services.

Simons, J. S., Dodson, C. S., Bell, D., \& Schacter, D. L. (2004). Specific- and partial-source memory: Effects of aging. Psychology \& Aging, 19, 689-694.

Spencer, W. D., \& Raz, N. (1995). Differential effects of aging on memory for content and context: A meta-analysis. Psychology \& Aging, 10, 527-539.

SQUIRE, L. R. (1992). Memory and the hippocampus: A synthesis from findings with rats, monkeys, and humans. Psychological Review, 99, 195-231.

Treisman, A., \& Schmidt, H. (1982). Illusory conjunctions in the perception of objects. Cognitive Psychology, 14, 107-141.

Yonelinas, A. P. (1994). Receiver-operating characteristics in recognition memory: Evidence for a dual-process model. Journal of Experimental Psychology: Learning, Memory, \& Cognition, 20, 1341-1354.

\section{ARCHIVED MATERIALS}

The following materials associated with this article may be accessed through the Psychonomic Society's Norms, Stimuli, and Data archive, www.psychonomic.org/archive.

To access these files or links, search the archive for this article using the journal name (Memory \& Cognition), the first author's name (Kersten), and the publication year (2008).

FILE: Kersten1-M\&C-2008.zip

DESCRIPTION: The compressed archive file contains one file:

Exp1Enc1.zip, containing 30 movie files from Experiment 1 Encoding List 1

FILE: Kersten2-M\&C-2008.zip

DESCRIPTION: The compressed archive file contains one file:

Exp1Enc2.zip, containing 30 movie files from Experiment 1 Encoding List 2

FILE: Kersten3-M\&C-2008.zip

DESCRIPTION: The compressed archive file contains one file:

Exp1Con1.zip, containing 30 movie files of Experiment 1 Conjunction Items from Retrieval List 1

FILE: Kersten4-M\&C-2008.zip

DESCRIPTION: The compressed archive file contains one file:

Exp1Con2.zip, containing 30 movie files of Experiment 1 Conjunction Items from Retrieval List 2

FILE: Kersten5-M\&C-2008.zip

DESCRIPTION: The compressed archive file contains one file:

Exp2Act.zip, containing Experiment 2 list of actions

AUTHOR's E-MAIL ADDRESs: akersten@fau.edu

(Manuscript received May 26, 2006; revision accepted for publication May 7, 2007.) 